\title{
Hemodynamic Congestion at Hospital Discharge Predicts Rehospitalization During Short Term Follow Up in Acute Heart Failure Patients
}

\author{
Yoga Waranugraha, M. Saifur Rohman, Setyasih Anjarwani
}

\begin{abstract}
Background: Hemodynamic congestion is an increase in left ventricular diastolic pressure (LVEDP) without clinical symptoms and signs of congestion. Current acute heart failure (AHF) treatment goals only focused on improving clinical congestion. The purpose of this study was to investigate whether hemodynamic congestion measured by NT-proBNP level and ePCWP at hospital discharge could predict short term clinical outcomes in AHF patients.

Methods: This prospective cohort study was conducted at dr. Saiful Anwar General Hospital Malang from January to July 20I8. All patients got AHF treatment according to the 2016 ESC guidelines for heart failure. All patients were discharged without symptoms and signs of clinical congestion. Hemodynamic congestion at hospital discharge was defined as failure of treatment during hospitalization to achieve NT-proBNP reduction of $>30 \%$ and/or ePCWP at hospital discharge $>16 \mathrm{mmHg}$. NT-proBNP level and ePCWP were measured at 0-12 hours after hospital admisssion and at hospital discharge. ePCWP was measured using echocardiography. The clinical outcomes assessed were AHF rehospitalization and cardiovascular mortality within 30 days after hospitral discharge. Subgroup analysis was performed to determine treatment regimen that are effective in improving hemodynamic congestion.

Results: A total of $33 \mathrm{AHF}$ patients were included in this study. $48 \%$ patients were discharged with hemodynamic congestion and $52 \%$ patients discharged without hemodynamic congestion. Patients with hemodynamic congestion at hospital discharge showed a higher rehospitalization within 30 days $(8[50 \%]$ vs I [5.9\%]; $\mathrm{P}=0.007)$. Mortality within 30 days in both groups did not show a significant difference (2 [12.5\%] vs 0 [0\%]; P = 0.277). Treatment regimen of optimal dose of ACEI/ARB, $\beta$-blocker, and diuretic was correlated with improvement of hemodynamic congestion $(P=0.026 ; r=0.454)$, NT-proBNP reduction of $>66 \%(P=0.02 ; r=0.574)$, and achievement of ePCWP $<16 \mathrm{mmHg}(\mathrm{P}=0.013 ; \mathrm{r}=0.493)$ at hospital discharge in HFrEF patients.

Conclusion: Hemodynamic congestion assessed using NT-proBNP level and ePCWP at hospital discharge increased 30 day rehospitalization in AHF patients. In HFrEF, improvements of hemodynamic congestion can be achieved by giving the treatment regimen of optimal dose of ACEI/ARB, $\beta$-blocker, and diuretic.
\end{abstract}

(Indonesian J Cardiol. 2019;40:290-300)

Keyword: Acute heart failure, hemodynamic congestion, NT-proBNP, ePCWP

Department of Cardiology and Vascular Medicine Faculty of Medicine, Universitas Brawijaya - Dr. Saiful Anwar General Hospital Malang

\section{Correspondence:}

Yoga Waranugraha, MD, FIHA

Department of Cardiology and Vascular Medicine

Faculty of Medicine, Universitas Brawijaya

dr. Saiful Anwar General Hospital Malang

E-mail: mr.waranugraha@gmail.com

\section{Introduction}

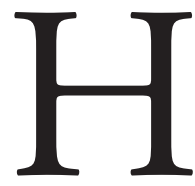

eart failure is a global pandemic problem, ${ }^{1}$ affecting more than 37.7 million people worldwide. According to the RISKESDAS 2013, the prevalence of heart failure in Indonesia was $0.3 \% .^{3}$ Patients with heart failure experience various kinds of clinical symptoms that 
can reduce the quality of life. ${ }^{2}$ Heart failure imposes a huge economic burden, estimated at 108 billion US dollar per year. AHF refers to rapid onset or worsening of symptoms and/or signs of heart failure. It is a life-threatening medical condition requiring urgent evaluation and treatment, typically leading to urgent hospital admission. 5 Despite therapeutic advances, the prognosis of acute heart failure is poor, with in-hospital mortality ranging from $4 \%$ to $7 \%, 60$ - to 90 -day mortality ranging from $7 \%$ to $11 \%$, and 60 - to 90 -day rehospitalization from $25 \%$ to $30 \%{ }^{6}$

Hemodynamic congestion is defined as high ventricular diastolic pressures without overt clinical signs. Clinical congestion may resolve with treatment but hemodynamic congestion may persist, leading to a high risk of rehospitalization. ${ }^{7,8}$ Data from studies with implantable hemodynamic monitors have confirmed that chronically elevated filling pressures or hemodynamic congestion are associated with increased risk of future events. ${ }^{9}$ Hemodynamic congestion could be assessed by increasing levels of NT-proBNP and PCWP. ${ }^{10,11}$ Several studies have shown that the relative NT-proBNP reduction of $<30 \%$ at hospital discharge is a significant predictor of mortality and rehospitalization in AHF patients. ${ }^{12,13}$ In AHF patients, achieving PCWP $<16 \mathrm{mmHg}$ at hospital discharge provides a better 1-year survival rate. ${ }^{14,15}$ PCWP can be estimated noninvasively using echocardiography. ${ }^{16,17}$ The purpose of this study was to investigate whether hemodynamic congestion measured by NT-proBNP level and ePCWP at hospital discharge could predict short term clinical outcomes in AHF patients.

\section{Methods}

\section{Study Design and Populations}

We conducted a prospective cohort study in dr. Saiful Anwar General Hospital Malang from January to June 2018. This research is a part of joint research by multi department entitled "Additive Value of Monitoring Non Invasive Cardiac Hemodynamic and Total Body Water Content in Critical Care Patients Outcomes in Acute Medicine Department from ER Admission to Discharge". This study involved AHF patients aged 40 years or more. Exclusion criteria included pregnancy, acute coronary syndrome, patients on invasive mechanical ventilation, cardiac arrest, cardiac tamponade, congenital heart disease, stenosis lesion of the heart valve, patients with mechanical or bioprostetic valves, left atrial myxoma, thrombus in the left atrium, thrombus in pulmonary vein, patient with cardiac implantable electronic devices (Pacemaker, ICD, or CRT), patient discharged from hospital without ACEI/ARB and/or $\beta$-blocker, patients discharged from hospital with clinical congestion, pulmonary embolism, pulmonary hypertension other than due to dysfunction left ventricle, COPD, pneumothorax, CKD, hyperthyroidism, stroke/TIA, malignancy, and terminal disease.

We performed measurement of NT-proBNP and ePCWP in AHF who came to the emergency room (ER) of dr. Saiful Anwar General Hospital in 0-12 hours after hospital admission. All patients received AHF therapy based on the 2016 ESC guidelines for heart failure. ${ }^{5}$ All patients are discharged from the hospital without symptoms and signs of clinical congestion. The second measurement of NT-proBNP and EPCWP was performed at hospital discharge. Patients were classified into 2 groups based on the presence of hemodynamic congestion at hospital discharge. Hemodynamic congestion at hospital discharge was defined as failure of treatment during hospitalization to achieve NTproBNP reduction of $>30 \%$ and/or ePCWP at hospital discharge $\geq 16 \mathrm{mmHg}$. The primary endpoints were AHF rehospitalization and cardiovascular mortality within 30 days after hospital discharge. Subgroup analysis was performed to determine the effective therapeutic regimen to achieve secondary endpoints which included hemodynamic congestion, NT-proBNP level, and ePCWP.

\section{BT-pro BNP and ePCWP Measurements}

NT-proBNP level was obtained from venous blood and processed using the sandwich-type electrochemiluminescence sensor method. ePCWP was measured using echocardiography. ePCWP was calculated using the formula ePCWP $=1.24 \mathrm{x}\left(\mathrm{E} / \mathrm{e}^{\prime}\right)+$ 1.9, $\mathrm{e}^{\prime}=\left(\right.$ lateral $\mathrm{e}^{\prime}+$ septal $\left.\mathrm{e}^{\prime}\right) / 2 .{ }^{18}$ For patients with single transmitral flow due to sinus tachycardia, ePCWP was calculated using the formula ePCWP $=1,47 \mathrm{x}\left(\mathrm{E} / \mathrm{e}^{\prime}\right)$ $+1,5 .{ }^{19}$ Whereas for patients with atrial fibrillation, ePCWP was calculated using the formula ePCWP = $0.821 \times\left(E / e^{\prime}\right)+6.489 .{ }^{17}$ In this study we used General 
Indonesian Journal of Cardiology

Table 1. Baseline characteristics of AHF patients at hospital admission

\begin{tabular}{|c|c|c|c|}
\hline & $\begin{array}{l}\text { Hemodynamic congestion }(+) \\
\mathrm{n}=16\end{array}$ & $\begin{array}{l}\text { Hemodynamic congestion (-) } \\
\qquad \mathrm{n}=17\end{array}$ & P-value \\
\hline Age, years, mean $+S D$ & $57,50 \pm 12,03$ & $66,47 \pm 12,25$ & 0,034 \\
\hline Men $(\%)$ & $10(62,5 \%)$ & $8(47,1 \%)$ & 0,373 \\
\hline NYHA IV functional class (\%) & $16(100 \%)$ & $17(100 \%)$ & - \\
\hline Dyspnea (\%) & $16(100 \%)$ & $17(100 \%)$ & - \\
\hline Orthopnea (\%) & $15(93,8 \%)$ & $11(64,7 \%)$ & 0,085 \\
\hline PND (\%) & $10(62,5 \%)$ & $11(64,7 \%)$ & 0,895 \\
\hline GCS, mean + SD & $15,00 \pm 0,00$ & $15,00 \pm 0,00$ & 1 \\
\hline $\mathrm{SBP}, \mathrm{mmHg}$, mean $+\mathrm{SD}$ & $144,63 \pm 37,17$ & $144,12 \pm 33,86$ & 0,986 \\
\hline DBP, mmHg, mean + SD & $85,88 \pm 17,58$ & $85,00 \pm 15,33$ & 0,828 \\
\hline MAP, $\mathrm{mmHg}$, mean + SD & $107,00 \pm 25,92$ & $105,18 \pm 20,69$ & 0,9 \\
\hline $\mathrm{HR}, \mathrm{bpm}$, mean $+\mathrm{SD}$ & $104,50 \pm 20,59$ & $106,00 \pm 15,14$ & 0,626 \\
\hline $\mathrm{RR}, \mathrm{tpm}$, mean $+\mathrm{SD}$ & $31,25 \pm 4,31$ & $30,00 \pm 3,67$ & 0,355 \\
\hline S3 (\%) & $4(25 \%)$ & $3(17,6 \%)$ & 0,688 \\
\hline Rhales (\%) & $16(100 \%)$ & $17(100 \%)$ & - \\
\hline $\mathrm{JVP}$ cmH2O, mean $+\mathrm{SD}$ & $9,19 \pm 1,79$ & $9,18 \pm 0,88$ & 0,573 \\
\hline Asites (\%) & $6(37,5 \%)$ & $1(5,9 \%)$ & 0,039 \\
\hline Hepatomegaly (\%) & $6(37,5 \%)$ & $6(35,3 \%)$ & 0,895 \\
\hline Leg edema (\%) & $10(62,5 \%)$ & $2(11,8 \%)$ & 0,002 \\
\hline Atrial Fibrillation (\%) & $4(25 \%)$ & $3(17,6 \%)$ & 0,688 \\
\hline Supraventricular arrhythmia (\%) & $1(6,3 \%)$ & $0(0 \%)$ & 0,485 \\
\hline Ventricular arrhythmia (\%) & $4(25 \%)$ & $3(17.6 \%)$ & 0,688 \\
\hline CTR, \%, mean + SD & $72,94 \pm 5,95$ & $69,71 \pm 4,82$ & 0,116 \\
\hline Interstitial congestion (\%) & $15(93,8 \%)$ & $17(100 \%)$ & 0,485 \\
\hline Alveolar congestion (\%) & $3(18,8 \%)$ & $2(11,8 \%)$ & 0,656 \\
\hline Pleural effusion (\%) & $2(12,5 \%)$ & $3(17,6 \%)$ & 1 \\
\hline Hemoglobin, g/dl, mean + SD & $13,46 \pm 2,62$ & $13,71 \pm 15,4$ & 0,719 \\
\hline NT-proBNP, pg/ml, mean + SD & $17547,75 \pm 12178,83$ & $13286,06 \pm 12788,50$ & 0,366 \\
\hline Ureum, mg/dl, mean $+\mathrm{SD}$ & $48,04 \pm 20,31$ & $50,73 \pm 28,51$ & 1 \\
\hline Creatinine, $\mathrm{mg} / \mathrm{dl}$, mean $+\mathrm{SD}$ & $1,39 \pm 0,54$ & $1,33 \pm 0,64$ & 0,614 \\
\hline $\mathrm{eGFR}, \mathrm{ml} / \mathrm{min} / 1.73 \mathrm{~m} 2$, mean $+\mathrm{SD}$ & $60,99 \pm 33,67$ & $61,5 \pm 28,29$ & 0,54 \\
\hline AST, mg/dl, mean + SD & $42,50 \pm 49,63$ & $28,18 \pm 16,16$ & 0,159 \\
\hline ALT, mg/dl, mean + SD & $33,38 \pm 45,34$ & $35,12 \pm 36,18$ & 0,287 \\
\hline Oxygen supplementation, $\%$, mean $+\mathrm{SD}$ & $77,06 \pm 27,54$ & $69,41 \pm 28,29$ & 0,299 \\
\hline $\mathrm{PH}$, mean $+\mathrm{SD}$ & $7,33 \pm 0,08$ & $7,39 \pm 0,10$ & 0,097 \\
\hline $\mathrm{PaCO} 2, \mathrm{mmHg}$, mean $+\mathrm{SD}$ & $35,43 \pm 11,76$ & $32,67 \pm 12,81$ & 0,387 \\
\hline $\mathrm{PaO} 2, \mathrm{mmHg}$, mean $+\mathrm{SD}$ & $112,36 \pm 44,34$ & $114,65 \pm 28,35$ & 0,494 \\
\hline $\mathrm{HCO} 3-, \mathrm{mmol} / \mathrm{l}$, mean + SD & $18,85 \pm 4,81$ & $19,59 \pm 4,18$ & 0,54 \\
\hline Base excess, $\mathrm{mmol} / \mathrm{l}$, mean $+\mathrm{SD}$ & $-8,56 \pm 3,55$ & $-6,08 \pm 4,43$ & 0,077 \\
\hline $\mathrm{SaO} 2, \%$, mean $+\mathrm{SD}$ & $95,85 \pm 3,82$ & $97,69 \pm 1,54$ & 0,97 \\
\hline RWMA (\%) & $13(81,3 \%)$ & $15(88,2 \%)$ & 0,656 \\
\hline EF Biplane, $\%$, mean + SD & $34,31 \pm 11,88$ & $35,88 \pm 8,89$ & 0,54 \\
\hline $\mathrm{E} / \mathrm{e}^{\prime}$, mean $+\mathrm{SD}$ & $18,42 \pm 3,05$ & $19,41 \pm 2,99$ & 0,46 \\
\hline ePCWP, mmHg mean + SD & $24,13 \pm 4,09$ & $25,35 \pm 3,90$ & 0,302 \\
\hline LVEDD, $\mathrm{cm}$, mean + SD & $5,98 \pm 1,15$ & $5,61 \pm 0,88$ & 0,517 \\
\hline LVESD, cm, mean + SD & $4,89 \pm 1,26$ & $4,69 \pm 0,97$ & 0,639 \\
\hline
\end{tabular}


Indonesian Journal of Cardiology

LAVI, $\mathrm{ml} / \mathrm{m} 2$ mean + SD

$50,56 \pm 15,54$

$49,94 \pm 14,63$

$14(82,4 \%)$

0,957

Mitral regurgitation (\%)

$14(87,5 \%)$

1

PND = Paroxysmal nocturnal dyspnea; GCS = Glasgow coma scale; SBP = Systolic blood pressure; DBP = Diastolic blood pressure; MAP = Mean arterial pressure; HR: heart rate; RR: respiratory rate; $\mathrm{S} 3$ = third heart sound; JVP = jugular venous pressure; $\mathrm{CTR}$ = cardiothoracic ratio; $\mathrm{eGFR}=$ Estimated glomerular filtration rate; AST = Aspartate aminotransferase; ALT = Alanine aminotransferase; $\mathrm{PaCO} 2$ = partial pressure of carbon dioxide in the arterial blood; $\mathrm{PaO} 2=$ partial pressure of oxygen in the arterial blood; HCO3- = bicarbonate; RWMA = regional wall motion abnormality; EF = Ejection fraction; E/e' = ratio between early mitral inflow velocity and mitral annular early diastolic velocity; LVEDD = left ventricular end systolic diameter; LAVI: left atrial volume index.

electronic Vivid e and Vivid 5 echocardiography machines. Echocardiographic examination was performed by two senior cardiology and vascular medicine residents. The interobserver variability was tested using the Cohen's Kappa test. No significant difference in echocardiography interpretations between both operators.

\section{Statistical Analysis}

Numerical variables are presented as mean \pm SD. Categorical variables are presented as frequencies and percentages. The comparison between 2 numerical variables was tested using the Mann Whitney test. The comparison between 2 categorical variables was tested using the Chi square test or Fisher's test. AHF rehospitalization and cardiovascular mortality within 30 days after hospital discharge were presented in the Kaplan-Meier curve. The cut off piont of some variables was tested using the ROC curve. The relationship between 2 nominal variables is tested using the contingency coefficient test. $\mathrm{P}$ value $\leq 0.05$ was considered statistically significant. All statistical analyses were performed using IBM SPSS Statistics 21.

\section{Results}

\section{Baseline Characteristics}

A total of 33 AHF patients with NYHA IV functional class were included in this study. $48 \%$ of patients were discharged from the hospital with hemodynamic congestion and $52 \%$ of patients were discharged from the hospital without hemodynamic congestion. In general, the basic characteristics of the two groups were not different. Patients discharged from the hospital with hemodynamic congestion were younger than patients discharged from the hospital without hemodynamic congestion $(57.50 \pm 12.03$ vs $66.47 \pm 12.25 ; \mathrm{P}=0.034)$. Ascites and limb edema at hospital admission were more prevalent in patients discharged from the hospital with hemodynamic congestion than in patients discharged from the hospital without hemodynamic congestion (6 $(37.5 \%)$ vs 1 (5.9\%); $\mathrm{P}=0.039$ and $10(62.5 \%)$ vs 2 (11.8\%); $\mathrm{P}=0.002$ respectively) (Table 1 ). The length of stay between the two groups was not different (Table 2). All patients were discharged from the hospital without clinical congestion. The treatment regimen at hospital discharge between the two groups were not different.

\section{Clinical outcomes}

Patients were followed for 30 days after hospital discharge. 30 day cardiovascular mortality in both groups was not significantly different (2 [12.5\%] vs 0 [0\%]; $\mathrm{P}=0,277)$. Patient with hemodynamic congestion at hospital discharge showed a higher 30 day rehospitalization than patient patient without hemodynamic congestion at hospital discharge (8 [50\%] vs $1[5.9 \%] ; \mathrm{P}=0.007)$. Survival analysis using Kaplan-Meier curve showed significant differences in 30 day rehospitalization after hospital discharge ( $\log$ rank, $\mathrm{P}=0.004$ ) but not mortality (Log rank, $P=0.138$ ) (Picture 1). After hospital discharge, daily drug dose regimen between the two groups were not different generally. Patients with hemodynamic congestion received a lower daily dose of furosemide than patients without hemodynamic congestion $(25.33+9.15 \mathrm{mg}$ vs. $33.33+9.75 \mathrm{mg} ; \mathrm{P}=$ $0.031)$ after hospital discharge (Table 4 ).

\section{Subgroup Analysis}

NT-proBNP is a well-known prognostic biomarker for AHF rehospitalization, but its value greatly varies among individuals. The ROC curve showed that the NT- 
Indonesian Journal of Cardiology

Table 2. Treatment during hospitalization

\begin{tabular}{lccc}
\hline & Hemodynamic congestion $(+)$ & Hemodynamic congestion (-) & P-value \\
\hline O2 supplementation (\%) & $\mathrm{n}=16$ & $\mathrm{n}=17$ & - \\
NIV (\%) & $16(100 \%)$ & $17(100 \%)$ & 0,601 \\
Inotropic (\%) & $2(12,5 \%)$ & $1(5,9 \%)$ & 1 \\
Diuretic (\%) & $2(12,5 \%)$ & $2(11,8 \%)$ & - \\
Nitrate (\%) & $16(100 \%)$ & $17(100 \%)$ & 0,579 \\
ACEI/ARB (\%) & $6(37,5 \%)$ & $8(47,1 \%)$ & - \\
CCB (\%) & $16(100 \%)$ & $17(100 \%)$ & 1 \\
MRA (\%) & $3(18,8 \%)$ & $4(23,5 \%)$ & 0,104 \\
OAC/NOAC (\%) & $9(56,3 \%)$ & $14(82,4 \%)$ & 0,688 \\
Antiplatelet (\%) & $4(25 \%)$ & $3(17,6 \%)$ & 0,398 \\
Statin (\%) & $12(75 \%)$ & $15(88,2 \%)$ & 0,601 \\
$\beta$-blocker (\%) & $14(87,5 \%)$ & $16(94,1 \%)$ & - \\
Digoxin (\%) & $16(100 \%)$ & $17(100 \%)$ & 0,656 \\
OAD (\%) & $2(12 \%)$ & $4(23,5 \%)$ & 0,601 \\
Insulin (\%) & $1(6,3 \%)$ & $3(17,6 \%)$ & 0,601 \\
Length of stay, day, mean + SD & $2(12,5 \%)$ & $1(5,9 \%)$ & 0,798 \\
\hline NIV $=$ Non invasive ventilation; ACEI
\end{tabular}

NIV = Non invasive ventilation; $\mathrm{ACEI}=$ Angiotensin converting enzyme inhibitor; $\mathrm{ARB}=$ Angiotensin receptor blocker; $\mathrm{CCB}$ $=$ Calcium channel blocker; $\mathrm{MRA}=$ Mineralocorticoid receptor antagonist OAC $=$ Oral anticoagulant NOAC $=$ Novel oral anticoagulant; $\mathrm{OAD}=$ Oral anti diabetes.

proBNP reduction during in-hospital treatment (cut off 66\%; sensitivity $75 \%$; specificity $76 \%$; AUC 0.755 ; P $=0.032)$ was better than single NT-proBNP value at hospital discharge (cut off $2813 \mathrm{pg} / \mathrm{mL}$; sensitivity $75 \%$; specificity $68 \%$; AUC $0.755 ; \mathrm{P}=0.032$ ) in predicting AHF rehospitalization (Picture 2).

We tried to find out the correlation between heart failure drug therapy regimen during in-hospital treatment with the achievement of secondary endpoints which included hemodynamic congestion, NTproBNP reduction of $>66 \%$, and ePCWP $<16 \mathrm{mmHg}$ at the hospital discharge. In the HFmrEF patients, administration of treatment regimen of optimal dose of ACEI/ARB, $\beta$-blocker, and diuretic was not associated with secondary endpoints (Table 5). Administration of treatment regimen of optimal dose of ACEI/ARB, $\beta$-blocker, and diuretic was associated with improvement of hemodynamic congestion $(P=0.026 ; r=0.454)$, NT-proBNP reduction of $>66 \%(\mathrm{P}=0.02 ; \mathrm{r}=0.574)$, and achievement of ePCWP $<16 \mathrm{mmHg}(\mathrm{P}=0.013$; $\mathrm{r}=0.493)$ at hospital discharge in the HFrEF patients (Table 6).

\section{Discussion}

In this study, we tried to combine biomarker and hemodynamic parameters measured noninvasively in assessing hemodynamic congestion. We used cut off point according to the results of several previous studies.12,13,14,15 Previous studies used pulmonary artery catheter to measure PCWP.14,15 No previous study used ePCWP measured by echocardiography as a hemodynamic parameter in AHF.

Hemodynamic congestion occurs within a few days or weeks before clinical congestion. ${ }^{20}$ In our study, the 30 day rehospitalization was higher in patient with hemodynamic congestion at hospital discharge. Patient with hemodynamic congestion suffered from symptoms of clinical congestion in few days or weeks after hospital discharge. Those conditions forced them for urgent hospital admission. In this study, patients who were discharged from the hospital with hemodynamic congestion received lower dose of furosemide. We were unable to intervene the therapeutic regimen which given by the physician in charge because our study design 
Table 3. Symptoms, signs, and medical treatment at hospital discharge

\begin{tabular}{|c|c|c|c|}
\hline & $\begin{array}{l}\text { Hemodynamic congestion }(+) \\
\mathrm{n}=16\end{array}$ & $\begin{array}{c}\text { Hemodynamic congestion }(-) \\
\mathrm{n}=17\end{array}$ & P-value \\
\hline Dyspnea (\%) & $0 \%$ & $0 \%$ & - \\
\hline Orthopnea (\%) & $0 \%$ & $0 \%$ & - \\
\hline PND (\%) & $0 \%$ & $0 \%$ & - \\
\hline GCS, mean + SD & $15,00 \pm 0,00$ & $15,00 \pm 0,00$ & 1 \\
\hline $\mathrm{SBP}, \mathrm{mmHg}$, mean + SD & $122,13 \pm 16,72$ & $117,41 \pm 19,21$ & 0,37 \\
\hline $\mathrm{DBP}, \mathrm{mmHg}$, mean + SD & $76,75 \pm 11,93$ & $71,29 \pm 6,20$ & 0,09 \\
\hline $\mathrm{MAP}, \mathrm{mmHg}$, mean + SD & $92,63 \pm 11,83$ & $86,59 \pm 9,25$ & 0,111 \\
\hline $\mathrm{HR}, \mathrm{bpm}$, mean $+\mathrm{SD}$ & $78,81 \pm 6,38$ & $74,76 \pm 6,60$ & 0,112 \\
\hline $\mathrm{RR}, \mathrm{tpm}$, mean $+\mathrm{SD}$ & $19,50 \pm 0,89$ & $19,24 \pm 0,97$ & 0,381 \\
\hline S3 (\%) & $0 \%$ & $0 \%$ & - \\
\hline Rhales (\%) & $0 \%$ & $0 \%$ & - \\
\hline $\mathrm{JVP}$ cmH2O, mean + SD & $6,44 \pm 0,63$ & $5,64 \pm 0,61$ & 0,002 \\
\hline Ascites (\%) & $0 \%$ & $0 \%$ & - \\
\hline Hepatomegaly (\%) & $0 \%$ & $0 \%$ & - \\
\hline Leg edema $(\%)$ & $0 \%$ & $0 \%$ & - \\
\hline Diuretic (\%) & $15(93,8 \%)$ & $15(88,2 \%)$ & 1 \\
\hline Nitrate (\%) & $8(50 \%)$ & $6(35,3 \%)$ & 0,393 \\
\hline ACEI/ARB (\%) & $16(100 \%)$ & $17(100 \%)$ & - \\
\hline ССВ (\%) & $3(18,8 \%)$ & $4(23,5 \%)$ & 1 \\
\hline MRA (\%) & $9(56,3 \%)$ & $14(82,4 \%)$ & 0,141 \\
\hline OAC/NOAC (\%) & $4(25 \%)$ & $3(17,6 \%)$ & 0,688 \\
\hline Antiplatelet (\%) & $11(68,8 \%)$ & $15(88,2 \%)$ & 0,225 \\
\hline Statin (\%) & $14(87,5 \%)$ & $16(94,1 \%)$ & 0,601 \\
\hline$\beta$-blocker (\%) & $16(100 \%)$ & $17(100 \%)$ & - \\
\hline Digoxin (\%) & $2(12,5 \%)$ & $4(23,5 \%)$ & 0,656 \\
\hline OAD (\%) & $1(6,3 \%)$ & $3(17,6 \%)$ & 0,601 \\
\hline Insulin (\%) & $2(12,5 \%)$ & $1(5,9 \%)$ & 0,601 \\
\hline
\end{tabular}

$\overline{\mathrm{PND}}=$ Paroxysmal nocturnal dyspnea; GCS = Glasgow coma scale; SBP = Systolic blood pressure; DBP = Diastolic blood pressure; MAP = Mean arterial pressure; HR: heart rate; RR: respiratory rate; S3: third heart sound; JVP: jugular venous pressure; $\mathrm{ACEI}=$ Angiotensin converting enzyme inhibitor; $\mathrm{ARB}=$ Angiotensin receptor blocker; $\mathrm{CCB}=$ Calcium channel blocker; $\mathrm{MRA}=$ Mineralocorticoid receptor antagonist; $\mathrm{OAC}=$ Oral anticoagulant; NOAC $=$ Novel oral anticoagulant; $\mathrm{OAD}=$ Oral anti diabetes

was an observational study. The decision of physician in charge to discharge the patient was made based on the absence of the clinical congestion according to the 2016 ESC guidelines for heart failure. ${ }^{5}$ We performed measurement of NT-proBNP level and ePCWP after the patients were decided to be discharged from the hospital by the physician in charge. Hemodynamic congestion and inadequate dose of furosemide could accelerate the occurrence of clinical congestion and rehospitalization. Moreover, there were several confounding factors which were difficult to be managed that could exacerbate AHF and rehospitalization such as acute coronary syndromes, non-compliance with medications, arrhythmia, or infection. In this study, cardiovascular mortality in both groups was not significantly different because the duration of follow-up is shorter than several previous 
Table 4. Daily dose of the heart failure drugs after hospital discharge

\begin{tabular}{lccc}
\hline \multicolumn{1}{c}{ Drugs } & Hemodynamic congestion $(+)$ & Hemodynamic congestion (-) & P-value \\
\hline Furosemide mg, mean + SD & $\mathrm{n}=16$ & $\mathrm{n}=17$ & 0,031 \\
Nitrat mg, mean + SD & $25,33+9,15$ & $33,33+9,75$ & 0,197 \\
Ramipril mg, mean + SD & $15,00+0,00$ & $18,33+6,61$ & 1 \\
Lisinopril mg, mean + SD & $10,00+0,00$ & $10,00+0,00$ & 1 \\
Valsartan mg, mean + SD & $20,00+0,00$ & $20,00+0,00$ & 0,536 \\
Candesartan mg, mean + SD & $192,00+121,33$ & $240,00+80,00$ & 0,157 \\
Spironolactone mg, mean + SD & $8,00+0,00$ & $16,00+0,00$ & 1 \\
Bisoprolol mg, mean + SD & $25,00+0,00$ & $25,00+0,00$ & 0,707 \\
Digoxin mg, mean + SD & $2,50+0,79$ & $2,35+0,41$ & 1 \\
\hline
\end{tabular}

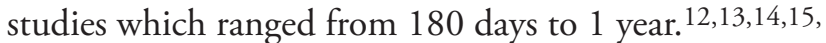

Our study supports the evidence that the failure in improving the hemodynamic congestion in AHF is associated with an increased risk of rehospitalization within 30 days after hospital discharge. Therefore, we conducted subgroup analysis to search for the treatment regimen to achieve secondary endpoints which included haemodynamic congestion, NT-proBNP reduction> $66 \%$, and PCWP achievement $<16$ when the patient discharged from the hospital. Patients were grouped into HFmrEF group and HFrEF group.

In HFmrEF patients, treatment regimen of optimal dose of ACEI/ARB, $\beta$-blocker, and diuretic was not correlated with improvement in hemodynamic congestion, NT-proBNP reduction of $>66 \%$, and achievement of ePCWP $<16 \mathrm{mmHg}$ at hospital discharge. These results may be caused by the heterogeneous pathophysiologic mechanism in HFpEF and HFmrEF. ${ }^{22,23}$ In the clinical trials and/or daily clinical practice, only a few patients with HFpEF and HFmrEF received ACEI/ARB, $\beta$-blocker, and diuretic compared to HFrEF patients. ${ }^{24,25,26}$ There is no effective treatment for reducing morbidity or mortality in HFpEF or HfmrEF patients. ${ }^{27}$ Neuro-hormonal antagonists (ACEIs, ARBs, MRAs, and $\beta$-blockers) have been shown to improve survival in patients with HFrEF and are recommended for the treatment of every patient with $\mathrm{HFrEF}$, unless contraindicated or not tolerated. Initiation and up-titration disease-modifying pharmacological therapy should be done immediately. In case of worsening of chronic HFrEF, every attempt should be made to continue evidence-based, disease- modifying therapies, in the absence of haemodynamic instability or contra-indications.5 In HFrEF patients, treatment regimen of optimal dose of ACEI/ARB, $\beta$-blocker, and diuretic was correlated with improvement in hemodynamic congestion, NT-proBNP reduction of $>66 \%$, and achievement of ePCWP $<16 \mathrm{mmHg}$ at hospital discharge. In this study, all patients received $\beta$-blocker during hospitalization after they had not shown clinical congestion and had previously received ACEI/ARB and diuretic. $\beta$-blocker up-titration also performed during hospitalization. In this study, $\beta$-blocker up-titration was faster than the guideline recommendations 5 or several previous studies. ${ }^{28,29,30}$ Our study supports the evidence that $\beta$-blocker initiation and up-titration during hospitalization are save for AHF patients as long as the clinical congestion has been resolved and the patients received optimal dose of ACEI/ARB and diuretics previously.

Our study has several limitations. First, single center study and the small number of samples cannot describe the real world conditions. Second, the short followup period makes it possible to provide biased results. Third, there were several confounding factors which were difficult to be managed that could exacerbate AHF and rehospitalization. Our study may be the first study using hemodynamic congestion measured by NTproBNP level and ePCWP as the predictors of shortterm clinical outcomes in AHF patients. We used very strict exclusion criteria to rule out comorbidities which can affect the result. 
Indonesian Journal of Cardiology

Table 5. Correlation between treatment regimen and the achievement of secondary endpoints in HFmrEF

\begin{tabular}{|c|c|c|c|c|c|c|}
\hline & & \multicolumn{3}{|c|}{ Optimal dose of ACEI/ARB $+\beta$-blocker + diuretic } & \multirow{2}{*}{$\mathrm{r}$} & \multirow{2}{*}{ P-value } \\
\hline & & No & Yes & Total & & \\
\hline \multirow{2}{*}{ NT-proBNP reduction of $>66 \%$} & No & $2(40 \%)$ & $2(22,2 \%)$ & $4(28,6 \%)$ & \multirow{2}{*}{0,185} & \multirow{2}{*}{0,48} \\
\hline & Yes & $3(60 \%)$ & $7(77,8 \%)$ & $10(71,4 \%)$ & & \\
\hline \multirow{2}{*}{$\mathrm{PCWP}<16 \mathrm{mmHg}$} & No & $2(40 \%)$ & $3(33,3 \%)$ & $5(35,7 \%)$ & \multirow{2}{*}{0,067} & \multirow{2}{*}{0,803} \\
\hline & Yes & $3(60 \%)$ & $6(66,7 \%)$ & $9(64,3 \%)$ & & \\
\hline \multirow{2}{*}{ Hemodynamic congestion } & No & $2(20 \%)$ & $7(77,8 \%)$ & $9(64,3 \%)$ & \multirow{2}{*}{0,353} & \multirow{2}{*}{0,158} \\
\hline & Yes & $3(60 \%)$ & $2(22,2 \%)$ & $5(35,7 \%)$ & & \\
\hline
\end{tabular}

$\overline{\mathrm{ACEI}}=$ Angiotensin converting enzyme inhibitor; $\mathrm{ARB}=$ Angiotensin receptor blocker; $\mathrm{ePCWP}=$ Estimated pulmonary capillary wedge pressure; NT-proBN $\mathrm{P}=\mathrm{N}$-terminal pro B-type natriuretic peptide; $\mathrm{HFmrEF}=$ Heart failure with midrange ejection fraction

Table 6. Correlation between treatment regimen and the achievement of secondary endpoints in HfrEF

\begin{tabular}{|c|c|c|c|c|c|c|}
\hline & & \multicolumn{3}{|c|}{ Optimal dose of ACEI/ARB $+\beta$-blocker + diuretic } & \multirow{2}{*}{$\mathrm{r}$} & \multirow{2}{*}{ P-value } \\
\hline & & No & Yes & Total & & \\
\hline \multirow{2}{*}{ NT-proBNP reduction of > 66\% } & No & $5(100 \%)$ & $3(21,4 \%)$ & $8(42,1 \%)$ & \multirow{2}{*}{0,574} & \multirow{2}{*}{0,02} \\
\hline & Yes & $0(0 \%)$ & $11(78,6 \%)$ & $11(57,9 \%)$ & & \\
\hline \multirow{2}{*}{$\mathrm{PCWP}<16 \mathrm{mmHg}$} & No & $5(100 \%)$ & $5(35,7 \%)$ & $10(52,6 \%)$ & \multirow{2}{*}{0,493} & \multirow{2}{*}{0,013} \\
\hline & Yes & $0(0 \%)$ & $9(64,3 \%)$ & $9(47,4 \%)$ & & \\
\hline \multirow{2}{*}{ Hemodynamic congestion } & No & $0(0 \%)$ & $8(57,1 \%)$ & $8(42,1 \%)$ & \multirow{2}{*}{0,454} & \multirow{2}{*}{0,026} \\
\hline & Yes & $5(100 \%)$ & $6(42,9 \%)$ & $11(57,9 \%)$ & & \\
\hline
\end{tabular}

\section{Conclusion}

Hemodynamic congestion assessed using NT-proBNP level and ePCWP at hospital discharge increased 30 day rehospitalization in AHF patients. Hemodynamic congestion can be considered as a therapeutic target in AHF patients during hospitalization. In HFrEF, improvements of hemodynamic congestion can be achieved by giving the treatment regimen of optimal dose of ACEI/ARB, $\beta$-blocker, and diuretic.

\section{Ethical Clearance}

This study had approved by Ethical Committee on Health Research of dr. Saiful Anwar General Hospital Malang with reference number: 400/02/K.3/302/2018.

\section{Publication approval}

The publication of this article has been approved by every party.

\section{Conflict of Interest}

None.

\section{Funding}

Research grant of Faculty of Medicine, Universtas Brawijaya, 2018.

\section{List of Abbreviations}

ACEI $=$ Angiotensin converting enzyme inhibitor

$\mathrm{ARB}=$ Angiotensin receptor blocker

$\mathrm{AHF}=$ Acute heart failure

AUC $=$ Area under the curve

CRT $=$ Cardiac resynchronization therapy

$\mathrm{CKD}=$ Chronic kidney disease

COPD $=$ Chronic obstructive pulmonary disease

$\mathrm{ePCWP}=$ Estimated pulmonary capillary wedge pressure 
Indonesian Journal of Cardiology
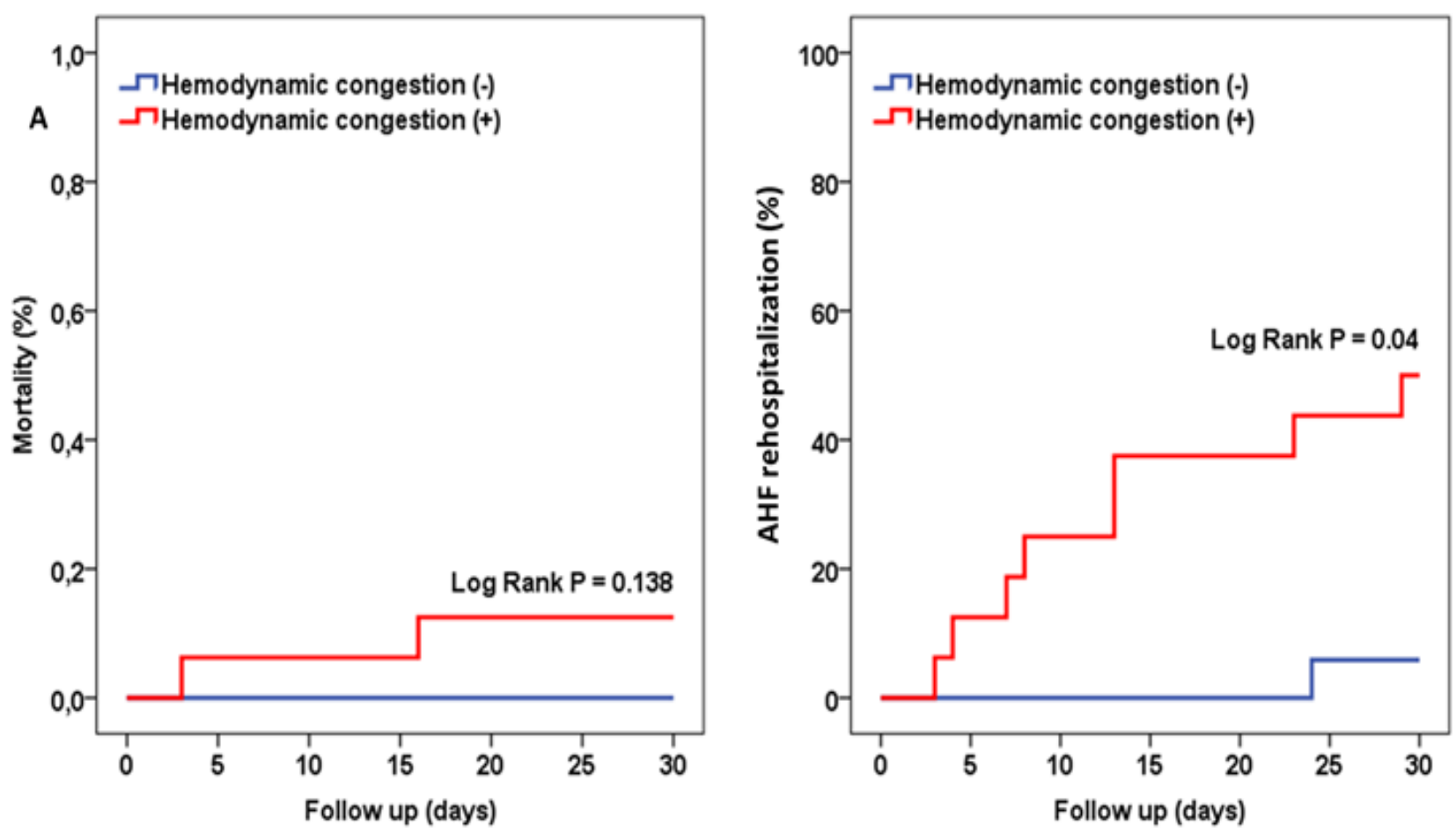

Figure 1. Kaplan-Meier Curve of 30 day cardiovascular mortality (A) and AHF rehospitalization (B)
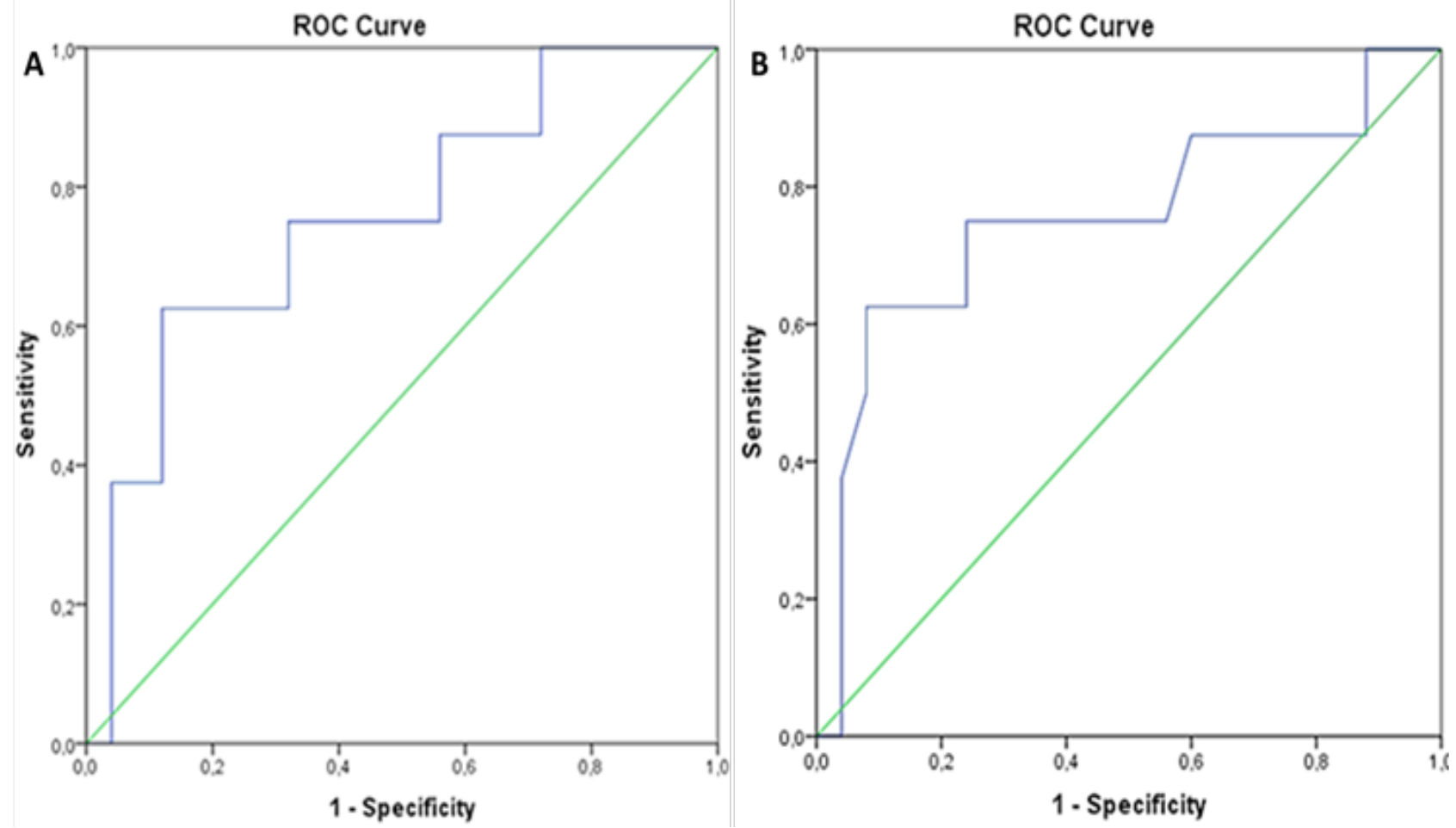

Figure 2. Receiver operating characteristic (ROC) to determine the NT-proBNP cut off. Single NT-proBNP value at hospital discharge $(\mathrm{A})$ and NT-proBNP reduction during in-hospital treatment (B) 
$\mathrm{ER}=$ Emergency room

$\mathrm{ESC}=$ European society of cardiology

$\mathrm{HFmrEF}=$ Heart failure with midrange ejection fraction $\mathrm{HFrEF}=$ Heart failure with reduced ejection fraction

ICD = Implantable cardioverter defibrillator

MRA = Mineralocorticoid receptor antagonist

NT-proBNP $=\mathrm{N}$-terminal pro B-type natriuretic peptide

NYHA $=$ New York heart association

PCWP = Pulmonary capillary wedge pressure

RISKESDAS $=$ Riset kesehatan dasar

$\mathrm{ROC}=$ Receiver operating characteristic

TIA $=$ Transient ischemic attack

\section{References}

1. Ponikowski P, Anker SD, AlHabib KF, Cowie MR, Force TL, Hu S, Jaarsma T, Krum H, Rastogi V, Rohde LE. Heart failure: preventing disease and death worldwide. ESC Heart Failure 2014; 1(1):425 .

2. Ziaeian B, Fonarow GC. Epidemiology and aetiology of heart failure. Nature Reviews Cardiology 2016; 13(6):368-378.

3. Badan Penelitian dan Pengembangan Kesehatan Kementerian Kesehatan Republik Indonesia. Laporan Riskesdas 2013. Hal: 90-91.

4. Cook C, Cole G, Asaria P, Jabbour R, Francis DP. The annual global economic burden of heart failure. International Journal of Cardiology 2014; 171(3):368-376.

5. Ponikowski P, Voors AA, Anker SD, Bueno H, Cleland JGF, Coats AJS, Falk V, Gonzalez-Juanatey JR, Harjola V-P, Jankowska EA. 2016 ESC Guidelines for the diagnosis and treatment of acute and chronic heart failure: The Task Force for the diagnosis and treatment of acute and chronic heart failure of the European Society of Cardiology (ESC) Developed with the special contribution of the Heart Failure Association (HFA) of the ESC. European heart journal 2016; 37(27):2129-2200.

6. Farmakis D, Parissis J, Lekakis J, Filippatos G. Acute heart failure: epidemiology, risk factors, and prevention. Revista Espanola de Cardiologia 2015; 68(3):245-248.

7. Felker GM, Teerlink JR. Diagnosis and Manage- ment of Acute Heart Failure. In: Mann DL, Zipes DP, Libby P, Bonow RO, eds. Braunwald's Heart Disease: A Textbook of Cardiovascular Medicine. 10 ed. Philadelphia, USA: Elsevier Saunders; 2014. p. 484-511.

8. Gheorghiade M, Filippatos G, De Luca L, Burnett J. Congestion in acute heart failure syndromes: an essential target of evaluation and treatment. The American journal of medicine 2006; 119(12):S3S10.

8. Stevenson LW, Zile M, Bennett TD, Kueffer FJ, Jessup ML, Adamson P, Abraham WT, Manda V, Bourge RC. Chronic ambulatory intracardiac pressures and future heart failure events. Circulation Heart failure 2010; 3(5):580-587.

10. Inomata T. Biomarkers: New Horizon for Heart 2 Failure Practice. In: Sato N, ed. Therapeutic Strategies for Heart Failure. Tokyo: Springer Japan; 2018. p. 17-38.

11. Vest AR, Jr. FH. Preload. In: Anwaruddin S, Martin JM, Stephens JC, Askari AT, eds. Cardiovascular Hemodynamics An Introductory Guide. Philadelphia, USA: Humana Press; 2013. p. 3-27.

12. Bayes-Genis A, Lopez L, Zapico E, Cotes C, Santalo M, Ordonez-Llanos J, Cinca J. NT-ProBNP Reduction Percentage During Admission for Acutely Decompensated Heart Failure Predicts Long-Term Cardiovascular Mortality. Journal of cardiac failure 2005; 11(5):S3-S8.

13. Salah K, Kok WE, Eurlings LW, Bettencourt P, Pimenta JM, Metra M, Bayes-Genis A, Verdiani V, Bettari L, Lazzarini V. A novel discharge risk model for patients hospitalised for acute decompensated heart failure incorporating $\mathrm{N}$-terminal pro-B-type natriuretic peptide levels: a European coLlaboration on Acute decompeNsated Heart Failure: ELANHF Score. Heart (British Cardiac Society) 2014; 100(2):115-125.

14. Fonarow GC, Stevenson LW, Steimle AE, Hamilton MA, Moriguchi JD, Walden JA, et al. Persistently high left-ventricular filling pressures predict mortality despite angiotensin-converting enzyme-inhibition in advanced heart failure. Circulation. 1994;90:488-488.

15. Fonarow GC. The treatment targets in acute decompensated heart failure. Reviews in cardiovascular medicine 2001; 2:S7-S12. 
16. J Romero-Bermejo F, Ruiz-Bailen M, Guerrero-De-Mier M, Lopez-Alvaro J. Echocardiographic hemodynamic monitoring in the critically ill patient. Current cardiology reviews 2011; 7(3):146156.

17. Pozzoli M, Traversi E, Roelandt J. Non-invasive estimation of left ventricular filling pressures by Doppler echocardiography. European Journal of Echocardiography 2002; 3(1):75-79.

18. Nagueh SF, Middleton KJ, Kopelen HA, Zoghbi WA, Quinones MA. Doppler tissue imaging: a noninvasive technique for evaluation of left ventricular relaxation and estimation of filling pressures. Journal of the American College of Cardiology 1997; 30(6):1527-1533.

19. Nagueh SF, Mikati I, Kopelen HA, Middleton KJ, Quinones MA, Zoghbi WA. Doppler estimation of left ventricular filling pressure in sinus tachycardia. Circulation 1998; 98(16):1644-1650.

20. Gheorghiade M, Follath F, Ponikowski P, Barsuk JH, Blair JEA, Cleland JG, Dickstein K, Drazner $\mathrm{MH}$, Fonarow GC, Jaarsma T. Assessing and grading congestion in acute heart failure: a scientific statement from the acute heart failure committee of the heart failure association of the European Society of Cardiology and endorsed by the European Society of Intensive Care Medicine. European journal of heart failure 2010; 12(5):423-433.

21. Stienen S, Salah K, Moons AH, Bakx AL, van Pol P, Kortz RAM, Ferreira JoP, Marques I, Schroeder-Tanka JM, Keijer JT. NT-proBNP (N-Terminal pro-B-Type Natriuretic Peptide)-Guided Therapy in Acute Decompensated Heart Failure: PRIMA II Randomized Controlled Trial (Can NT-ProBNP-Guided Therapy During Hospital Admission for Acute Decompensated Heart Failure Reduce Mortality and Readmissions?). Circulation 2018; 137(16):1671-1683.

22. Senni M, Paulus WJ, Gavazzi A, Fraser AG, Diez J, Solomon SD, Smiseth OA, Guazzi M, Lam CSP, Maggioni AP. New strategies for heart failure with preserved ejection fraction: the importance of targeted therapies for heart failure phenotypes. European heart journal 2014; 35(40):2797-2815.

23. Ferrari R, Bohm M, Cleland JGF, Paulus WJS, Pieske B, Rapezzi C, Tavazzi L. Heart failure with preserved ejection fraction: uncertainties and di- lemmas. European journal of heart failure 2015; 17(7):665-671.

24. Maggioni AP, Anker SD, Dahlstrom U, Filippatos G, Ponikowski P, Zannad F, Amir O, Chioncel O, Leiro MC, Drozdz J. Are hospitalized or ambulatory patients with heart failure treated in accordance with European Society of Cardiology guidelines? Evidence from 12440 patients of the ESC Heart Failure Long-Term Registry. European journal of heart failure 2013; 15(10):1173-1184.

25. Pitt B, Pfeffer MA, Assmann SF, Boineau R, Anand IS, Claggett B, Clausell N, Desai AS, Diaz R, Fleg JL. Spironolactone for heart failure with preserved ejection fraction. New England Journal of Medicine 2014; 370(15):1383-1392.

26. Solomon SD, Zile M, Pieske B, Voors A, Shah A, Kraigher-Krainer E, Shi V, Bransford T, Takeuchi $\mathrm{M}$, Gong J. The angiotensin receptor neprilysin inhibitor LCZ696 in heart failure with preserved ejection fraction: a phase 2 double-blind randomised controlled trial. The Lancet 2012; 380(9851):13871395.

27. Fukuta H, Goto T, Wakami K, Ohte N. Effects of drug and exercise intervention on functional capacity and quality of life in heart failure with preserved ejection fraction: a meta-analysis of randomized controlled trials. European journal of preventive cardiology 2016; 23(1):78-85.

28. Poole-Wilson PA. The Cardiac Insufficiency Bisoprolol Study II. Lancet (London, England) 1999; 353(9161):1360-1361.

29. Willenheimer R. How to begin treatment in chronic heart failure? Results of CIBIS III. European Heart Journal Supplements 2006; 8(suppl_C):C43-C50.

30. Willenheimer R, Erdmann E, Follath F, Krum H, Ponikowski P, Silke B, Van Veldhuisen DJ, Van De Ven L, Verkenne P, Lechat P. Comparison of treatment initiation with bisoprolol vs. enalapril in chronic heart failure patients: rationale and design of CIBIS-III. European journal of heart failure 2004; 6(4):493-500. 